\title{
RESEARCH IN DECLINE
}

Research in psychiatry is in decline. Fifteen years ago it was the ambition of many registrars in training to do some investigation and publish a paper, and the favoured few at the Maudsley even got an extra degree (the M. Phil.) out of it. People thought it would help them to a consultant post. Now they know it is not necessary. Training has become more formalized, with day-release courses and rotation schemes; and research seems more difficult, often needing specialized service or complex instruments and thousands of pounds.

"Seems" is the imnortant word here because for some areas of important research all one needs is patients, paper and pencil, and some brains. In other areas one may want in addition a bit of help from the path. lab., or a professional colleague or two (nurse, teacher, social worker, etc.), but this is a matter of friendly approach and organization, not of funds, mass spectrographs or a knowledge of electronics. For example, keeping depressed patients awake all night is known to improve some of them markedly: is this unexpected effect (with implications for therapy and pathology) a result simply of being awake, or of positive mental activity, or of the upright posture, or of additional food and drink, and is it additive to the benefits of other physical therapies (ECT, tricyclic drugs, lithium carbonate, etc)? It is claimed that schizophrenic illnesses may be in some sense caused or worsened by wheat proteins, as coeliac disease is by gluten: why in this country of the double-blind trial has no one attempted a proper scientific test of this important possibility? Why don't people follow up their old patients one or two years after treatment, to see what became of them? Why haven't there been more studies to see whether hospitalization for only one week is as good in outcome as a stay for four, or whether a 15-minute out-patient interview is as good as an hour?

Research is not just high-flown stuff about dopamine or HLA antigens or brain scans, but about the down-to-earth work of everyday practice. But it means asking questions instead of simply plodding through the routine. Are you spending your time wisely, are you doing your patients enough good, is this conventional treatment for depression or alcoholism or anxiety symptoms really working? Is it true that life events precipitate attacks of mania, or unloving mothers generate schizophrenia in their offspring? How many agoraphobics are there in your catchment area?

This is why a decline in research is bad. It is a decline in curiosity, in intellectual independence and the questioning of authority, in the will to better practice, whether individually or as a health service to the community. How can education and training, the College's concern, help to awaken this curiosity, this will to better practice?

If one looks at the papers submitted to the Jourmal from British mental hospitals, one can see among the rejects what some of the problems are for those who do attempt research. The biggest is isolation. People embark on an inquiry without bothering to read anything of what has already been published and attempted in this field. A bit of reading would show the pitfalls of inquiry and how to avoid them, or maybe raise a few questions or explanations the would-be researcher had not thought of but will need to consider. Of course the necessary books and journals are not absolutely to hand and perhaps the right sort of reading list is not obvious anyway. Perhaps psychiatrists need teaching how to use a library-and a librarian-and the way to get hold of uncommon journals and books.

Another common problem is haste. People embark on studies before they have given enough time to thinking them out (discussion with one or two others can be very helpful here). They probably never wrote down first a synopsis of their complete plan of study, giving the actual practical details of how they will do it. This may involve defining beforehand what is meant by a life-event, for example, so that one can recognize the relevant ones when they turn up; or what is meant by clinical improvement; but also deciding how many cases will be needed, and therefore how many months or years the inquiry will take. The work of making a preliminary synopsis may reveal the need for statistical or psychological or other specialist advice, or show that the research cannot, in fact, be carried out in the time or with the facilities available.

Examples of a few failures may help. Someone made a study of a year's experience of overdose cases admitted to his general hospital. But he didn't ask himself whether the cases were representative of his catchment area, or what became of them after discharge, so what use was that? Research is a matter of turning up not just facts interesting to the researcher but data which can be compared with those of other workers, or which can be used to settle some practical question of management or aetiology. Someone else set up a study of sleep deprivation and got his local lab to measure the plasma cortisol in samples of blood drawn at 2 a.m. from people asleep or awake at that time. What a pity to go to all that trouble and end up with a totally inadequate biochemical approach. It has 
been known for some time that the plasma cortisol Huctuates widely and only a series of samples taken every 15 minutes or so can answer this question. A single sample is useless. Much better here to have made a purely clinical study of sleep deprivation. Other people have inquired into the attitudes of patients to being compulsorily detained, or to being interviewed in public, but they haven't got a big enough sample, or a random sample, or they've only studied the work of one clinical team. With better preparation and little more active work, they could have done much better.

The College Research Committee sees part of its function as helping people to undertake research, particularly those in non-teaching hospitals who see such a volume of clinical problems. It has been wondering whether to set up a sort of advisory service to which isolated members could appeal for advice about their research plans, their reading, and their introduction to other workers in the field, particularly those in neighbouring academic centres who might be willing to discuss aspects of a project. It wonders whether a system of regional research tutors, analogous to the clinical tutors, would be helpful, or whether the advisory service should be simply from Belgrave Square. It has sent out a letter of inquiry about all this to Divisional Secretaries, but would be glad to hear directly, or through a letter to the Bulletin what any member thinks might help. What would make it easier for people to conduct good inquiries in the course of their NHS work?

John L. Crammer

\section{REPORTS AND PAMPHLETS}

Report of a Symposium on Chronic Mental Illness. The DHSS Worcester Development Project symposium held at Worcester on 5 October, 1978.

The Report contains talks by Professors John Wing and Eric Sainsbury, by Dr Christine Hassall of the Worcester Development Project Evaluation Team, University of Birmingham, and by three local contributors. There are reports from six discussion groups and an Appendix (B) by the Mental Health Division of the DHSS carrying a background note on the Worcester Development Project.

The foreword poses practical and theoretical questions for discussion, and $\mathrm{Dr} \mathrm{P}$. Mason tries further to refine the problem by identifying five basic questions for consideration.

Wing discusses alternative facilities, pointing out that hostels, group homes and day centres do not cater for the most severely disabled and that daytime occupation is a major problem for the substantial group who will spend most of their time outside hospital but will still require a high degree of continuous or intermittent care which is not at present provided. In discussion, he 'readily admitted' that there is no ideal method of deciding the type of care most appropriate in any particular case.

Professor Sainsbury talked of difficulties with mental health work as being related to lack of resources, to poor professional relationships, to low departmental priority leading to shortage of time and to inadequate skills. Although the aims and objectives of social policy are agreed, this 'agreement exists sometimes more in the expression of good intentions than within the activities of day-to-day practise'.
Dr Hassall presented a description of long-term patients from the Worcester Case Register. She did not consider the 'old long-stay patients' nor those with 'cumulative chronicity', i.e. those who have not spent more than 12 months continuously in one service but who may have several contacts of short duration within a like period.

Dr Hall presented 'the conception, gestation and imminent birth of the Worcester Development Project' as an unproven experiment. He was 'not too displeased that Powick will continue to exist' saying that the only way in which the Worcester Development Project approach is unique is in 'our almost total rejection of long-term institutional care of any kind'. Chronic patients of the 1980s may be different from those of the past, and the environment to which they are discharged may be more institutional than hospital. He spoke of the possibly intolerable burden on relatives imposed by 'an unduly partisan community-based service'.

Mr R. Wix introduced the nurses' view, enumerating the components necessary for comprehensive health district service.

Mrs Jaynes of an Area Social Services Department described a small group who made the transition from hospital care to community care and pointed out how limited community services are at night, at week-ends and at holiday times.

The groups discussed various topics, e.g. day hospitals and day centres (no difference in their clienteles), domiciliary care and family support (more help for relatives from general practitioners, crisis intervention teams), the problem of drifters (more research) and voluntary organizations ('there is indeed 